\title{
Posições e segmentos de classes sociais na Região Metropolitana de Natal na década de 1990
}

\author{
Positions and segments of social classes \\ in the Metropolitan Region of Natal in the 19905
}

Marconi Gomes da Silva [I]

\begin{abstract}
Resumo
A década de 1990, considerada a segunda década perdida, apresentou baixa dinâmica produtiva e do mercado de trabalho no Brasil e na Região Metropolitana de Natal (RMN). No presente artigo, considera-se que o mercado de trabalho apresenta as classes sociais cada vez mais segmentadas. Seguindo essa perspectiva, este trabalho baseou-se em Santos (2002) para estudar a segmentação no mercado de trabalho como proxy das posições e segmentos de classes sociais na realidade estudada. A hipótese norteadora do trabalho é que a posse de ativos materiais assim como qualificação e posições de mando são cruciais para assumir meIhores posições na estrutura de classes do ponto de vista da distribuição. A análise dos dados empíricos permite aumentar o grau de confiança na hipótese formulada.
\end{abstract}

Palavras-chave: estrutura ocupacional; mercado de trabalho; classes sociais; segmentos sociais; Região Metropolitana de Natal.

\begin{abstract}
The 1990s, seen as the second lost decade, presented low dynamics of production and of the labor market in Brazil and in the Metropolitan Region of Natal (Northeastern Brazil). In this article, we consider that the labor market shows that the social classes are becoming increasingly segmented. Following this perspective, the article was based on Santos (2002) to study the segmentation of the labor market as a proxy for positions and segments of social classes in the analyzed reality. The hypothesis that guides the article is that possession of material assets, as well as qualification and command positions, are crucial to take on better positions in the structure of classes from the distribution standpoint. The analysis of the empirical data allows to increase the level of trust in the formulated hypothesis.
\end{abstract}

Keywords: occupational structure; labor market; social classes; social segments; Metropolitan Region of Natal. 


\section{Breve introdução teórica e metodológica ao tema das classes sociais na contemporaneidade}

Vários são os estudos que têm abordado as classes sociais em sociedades capitalistas no período recente, ou seja, da década de 1970 até o final do segundo e início do terceiro milênio. Dentre eles, podem ser destacados: $A$ estrutura de classes das sociedades avançadas (Giddens, 1975); As classes sociais no capitalismo de hoje (Poulantzas, 1978); A nova classe média (Mills, 1979); Classe, crise e o Estado (Wright, 1981); The debate on classes (Wright et al., 1989); Class counts (Wright et al., 1997); Trabalho e capital monopolista (Braverman, 1977); Aspectos da crise social no Brasil dos anos oitenta e noventa (Quadros, 2003); Espacialização de classes no Brasil (Maia, 2006).

Em que pese a importância das obras supracitadas à compreensão das classes sociais na contemporaneidade, destaca-se aqui, em decorrência dos propósitos do presente artigo, o estudo realizado por Santos (2002), intitulado Estrutura de posições de classe no Brasil: mapeamento, mudanças e efeitos na renda. Nesse estudo, Santos utiliza como principal autor de referência Erik Olin Wright e como base empírica as Pesquisas Nacionais por Amostra de Domicílio (Pnads), realizadas nos anos de 1982 e 1986 pelo Instituto Brasileiro de Geografia e Estatística (IBGE), para elaborar um mapeamento da estrutura de classes sociais no Brasil. A ideia aqui defendida é que o autor conseguiu uma excelente aproximação da estrutura de classes no Brasil a partir da base empírica já referida, e, por esse motivo, o estudo em pauta constitui-se como suporte fundamental para o presente artigo, embora este tenha por base empírica os censos demográficos.

A princípio, é importante destacar que Santos efetuou vários ajustamentos às tipologias utilizadas por Wright, sobretudo em decorrência das especificidades das fontes de dados utilizadas. Entretanto, neste item do artigo, não cabe tratar de tais modificações, mas do cerne do tratamento teórico utilizado pelo autor. Assim, procede-se, a seguir, a uma breve aproximação da elaboração teórica de Erik 0 . Wright tendo como base o texto destinado ao referencial teórico apresentado por Santos (ibid.).

Embora tivesse preocupação com o estudo do conjunto das classes sociais, Wright precisou dar atenção especial a uma temática cara ao pensamento marxista: as classes médias. Dado que as classes médias constituem assunto controverso na literatura marxista, é necessário destacar que Wright se posicionou no debate como defensor da perspectiva segundo a qual as classes médias se caracterizam, a princípio, por representarem "localizações contraditórias dentro das relações de classe", sendo o caráter contraditório das localizações decorrente do compartilhamento de "características relacionais de duas classes distintas". 0 primeiro mapa de classes foi elaborado levando em consideração os processos de dominação e subordinação dentro da produção a partir da posse de capital monetário, de capital físico e de "trabalho" (ibid., p. 38).

Em seguida, Wright passou a considerar a exploração como o centro da sua análise de classe, sendo a ideia-chave a de que "a exploração material é determinada pelas desigualdades na distribuição dos ativos produtivos" (ibid., p. 38). Então, a posse de tais ativos tenderia a gerar interesses antagônicos, 
pois determinados segmentos sociais passam a desfrutar de boas condições de vida às expensas de outros. $O$ entendimento é que os "Ativos produtivos são fatores ou recursos produtivos geradores de renda". Segundo essa acepção de ativos, a ideia de exploração seria, então, aplicável tanto aos proprietários de meios de produção, como a alguns segmentos das classes médias, relativamente aos produtores da riqueza social por serem detentores de ativos de qualificação. Seria, nesse sentido, a desigualdade na distribuição desses ativos, a base para as "transferências de trabalho excedente" e para a estrutura de classes e os conflitos de classes (ibid., p. 43). Embora chame a atenção para o fato de que "as diversas dimensões da desigualdade social não possam ser reduzidas à desigualdade de classes", considera que "as relações de classe jogam um papel decisivo na moldagem das outras formas de desigualdade", como é o caso da desigualdade de renda, pois "as posições de classe moldam a forma como outras causas influenciam a renda" (ibid., p. 44).

Wright trabalhou também com a ideia de que no capitalismo, além da exploração capitalista, havia espaço para a exploração não propriamente capitalista, embora Ihe fosse subordinada. Então, ganha importância a ideia de "localizações contraditórias de classe". Essas localizações seriam exercidas pelos integrantes das posições intermediárias em função da "existência de ativos organizacionais". Considera a organização um ativo por implicar a "tomada de decisão coordenadora sobre uma complexa divisão técnica do trabalho" (ibid., p. 44). Nesse contexto, o papel exercido pelos gerentes seria fundamental, em decorrência da participação nas relações de dominação e da "localização privilegiada de apropriação [...] dentro das relações de exploração" (Santos, 2002, p. 45); tal papel lhes garante "a percepção de 'rendas de lealdade'" (ibid., p. 45).

Santos (ibid.) apresentou duas versões das tipologias de classe elaboradas por Wright, sendo uma denominada "básica" e a outra "desenvolvida". Alude, inicialmente, à diferença entre classes e localizações ou posições de classe. Afirma: as "classes caracterizam-se pela sua localização dentro das relações sociais de produção" enquanto as localizações ou "ocupações representam posições definidas no âmbito das relações técnicas de produção" (ibid., p. 47); "as localizações de classe estão sempre estruturalmente interconectadas às relações de classe", por isso "a noção de estrutura de classes designa a organização de conjunto de relações e localizações de classe" (ibid., p. 50).

A tipologia de classes elaborada por Wright referente às sociedades capitalistas teve, no caso da versão básica, seis localizações de classe, enquanto, na versão desenvolvida, teve doze localizações (ibid.). Em ambos os casos, as tipologias foram elaboradas "em função da apropriação diferenciada de ativos em meios de produção, ativos de qualificação e relação com o exercício de dominação dentro da produção (caracterizados antes como ativos organizacionais)". Afirma Santos (ibid., p. 49) que "a parte crítica [...] encontra-se [...] nas divisões internas entre os assalariados".

Pelo fato de a tipologia desenvolvida constituir-se aprofundamento da tipologia básica, a referência será àquela, por ser mais ampla. A primeira distinção quanto às posições de classes diz respeito ao controle dos meios de produção. Segundo esse critério classificatório, têm-se, de um lado, os proprietários ou 
detentores de meios de produção e, de outro, os não proprietários ou trabalhadores assalariados. No caso dos proprietários de meios de produção ou de ativos materiais, as posições de classe são: burguesia, pequenos empregadores e pequena burguesia. 0 critério fundamental utilizado na classificação é o aporte de capital. No caso da primeira posição, a burguesia, têm-se aqueles cujo aporte de capital é suficientemente grande, de modo que lhes permite viver exclusivamente do trabalho de outrem. No caso da segunda, o aporte de capital atinge uma magnitude que permite empregar pessoas, mas impõe ainda a necessidade de "trabalhar". A terceira posição diz respeito a detentores de meios de produção, cujo aporte é insuficiente para empregar pessoas. Já a classe considerada intermediária ou classe com posição contraditória tem as suas posições de classe definidas pelo critério de relação com a autoridade. São seis as posições nas quais são classificados gerentes e supervisores. Essas posições são adjetivadas de especialistas, qualificados e não qualificados e, portanto, como resultado, têm-se três tipologias para gerentes e três para supervisores. As posições de gerentes e supervisores caracterizam-se pelo exercício de algum nível de autoridade em relação aos trabalhadores. Entretanto, o caráter distintivo de tais posições é que, se os supervisores assumem posição de autoridade sobre os trabalhadores, os gerentes caracterizam-se por exercer também autoridade sobre segmentos subordinados e por participarem da tomada de decisões estratégicas nas organizações. Por fim, na tipologia de classes em pauta, têm-se os segmentos compostos pelos não gerentes especialistas, os trabalhadores qualificados e, na base da estrutura, os trabalhadores não qualificados.
Santos, além de apresentar uma resenha das "críticas ao esquema de classes de Erik Olin Wright", procedeu, ainda, a uma reelaboração das tipologias daquele autor, considerando as especificidades das fontes de que fez uso e, ademais, levando em consideração as especificidades da realidade que se constituiu em objeto do seu estudo. Finalizando, é importante destacar que Santos defende a relevância do trabalho de Wright, sobretudo por se tratar de estudo voltado à "pesquisa empírica sistemática" e por se tratar de teoria e tipologia que "inscrevem-se em uma obra aberta e em progresso" (ibid., p. 68). Foi com base nessa avaliação que Santos utilizou Erik Olin Wright como autor de referência para o estudo de posições de classe no Brasil. Igual razão é levada em consideração com relação ao estudo de Santos (2002) para a construção das tipologias das posições de classe apresentadas no próximo item do estudo.

\section{Considerações metodológicas sobre a temática das classes sociais com base nos censos demográficos}

A presente parte do estudo tem caráter eminentemente empírico e destaca apenas as pessoas ocupadas, com base nos microdados dos censos demográficos, sob a perspectiva das posições e dos segmentos de classe. Considera-se que a estrutura presente no mercado de trabalho se constitui uma boa aproximação do que ocorre na sociedade.

Coerentemente com a orientação teórica da pesquisa, tendo como âncoras Marx e autores marxistas, a opção foi por tomar como 
tipologia de referência a utilizada por Santos (2002). 0 autor baseou-se em estudos elaborados por Erik Olin Wright para proceder à organização dos dados das Pesquisas Nacionais por Amostra de Domicílios (Pnads) de 1981 e 1996. Porém, como o estudo ora desenvolvido baseia-se nos censos demográficos, foi necessário fazer uso adicional do trabalho desenvolvido pela Comissão Nacional de Classificação (Concla) - criada para o monitoramento, a definição de normas de utilização e a padronização das classificações estatísticas nacionais - para efetuar a sistematização das informações alusivas ao ano de 2000, uma vez que, nesse ano, o Instituto Brasileiro de Geografia e Estatística (IBGE) utilizou novas classificações para as atividades econômicas e as ocupações. Por conseguinte, foi necessário observar se ocorreu desagregação ou agregação das ocupações constantes no Censo Demográfico de 1991 (IBGE, 1991) para promover a distribuição das pessoas ocupadas segundo os segmentos de classes. ${ }^{1}$

É verdade que as pessoas desde o nascimento se encontram implicadas em diferenciações sociais e, portanto, integram distintas classes sociais. Por esse motivo, Santos (ibid.) apresentou dois mapeamentos de posições de classe. Em um deles posicionou o indivíduo ativo e ocupado no mercado de trabalho e, em outro, considerou as pessoas de referência das famílias. Na presente pesquisa, a opção foi feita apenas pelo posicionamento das pessoas ativas e ocupadas no mercado de trabalho nos períodos de referência dos censos demográficos.

O critério norteador utilizado para a localização das pessoas, segundo a posição e os segmentos de classes, foi o controle de ativos produtivos, sendo estes entendidos como "fatores ou recursos produtivos geradores de renda" (ibid., p. 43). Na realidade, os ativos podem ser redefinidos como fatores que possibilitam participar do processo de produção ou de prestação de serviços e da apropriação da renda gerada em um período de referência.

As categorias que expressam as posições na ocupação, tal como afirmou Santos (ibid.) referindo-se às informações das Pnads, dizem respeito a formas históricas da divisão do trabalho em sociedades capitalistas. Partindo-se dessa constatação, as posições de empregador, conta própria e empregado são tomadas como básicas para a construção da tipologia de posições e segmentos de classe. Além de tais posições, considera-se, também, o controle sobre os ativos - de capital, de ordem organizacional, de qualificação ou com fundamento no trabaIho "simples"' -, que permite participação na produção e na prestação de serviços, bem como a participação da distribuição da renda.

Com base em tais critérios, os grupos ocupacionais constantes dos Censos Demográficos de 1991 (IBGE, 1991) e de 2000 (IBGE, 2000) foram distribuídos por vinte segmentos de classe. Destaca-se que são 381 e 510, as quantidades de grupos ocupacionais constantes, respectivamente, dos Censos Demográficos de 1991 e 2000. A posição de Empregador foi definida pelo controle de ativos de capital que permitem empregar pessoas. 0 segmento dos Grandes empregadores compreende os detentores de grandes aportes de capital, implicando comando sobre uma grande quantidade de trabalhadores. $\mathrm{O}$ segmento dos $\mathrm{Pe}$ quenos empregadores mais capitalizados é composto por empregadores que detêm aportes menores de capitais, mas que permitem viver apenas do trabalho de outrem. Por sua vez, os Pequenos empregadores menos capitalizados são detentores de aportes ainda menores 
de capital e geralmente se envolvem diretamente com as atividades nas quais atuam, pelo fato de não conseguirem viver exclusivamente do trabalho de outrem.

A posição de autoempregado, identificada normalmente com a ocupação na condição de "conta própria", dada a grande diversidade de atividades desenvolvidas, foi segmentada, a princípio, levando-se em consideração o fato de os "conta própria" serem detentores ou não de "ativos de qualificação". Os detentores de ativos de qualificação credenciada foram classificados como autoempregados especialistas e os não detentores, a princípio, foram classificados como autoempregados não especialistas em atividades rurais e urbanas. Os primeiros foram classificados como autoempregados na agropecuária pelo fato de se envolverem diretamente com essas atividades. Os autoempregados urbanos foram definidos com base nos "aportes de capital" que detinham, por isso foram classificados em autoempregados capitalizados e autoempregados descapitalizados.

A condição de trabalhador é assumida pelos que atuam como empregados. Trata-se de um agrupamento muito heterogêneo no que concerne aos fatores que propiciam a participação na produção e na prestação de serviços e, por conseguinte, na apropriação da renda. Uma parcela dos empregados é detentora de "ativos organizacionais", o que permite o exercício de autoridade em ambiente empresarial, por delegação dos efetivos mandatários, ou em instituições públicas. Logo, esse conjunto é integrado por trabalhadores que atuam como dirigentes do setor privado ou como dirigentes do setor público. É verdade que cada um desses segmentos é passível de nova segmentação, considerando-se a natureza do cargo ou a função exercida ou em decorrência de qualificação credenciada.

Parte do contingente dos trabalhadores tem participação na produção ou prestação de serviços, fundamentalmente, em decorrência do fato de deterem ativos de qualificação. Os detentores de qualificação credenciada, "qualificações escassas" ou que dominam "sistemas peritos" foram considerados como trabalhadores especialistas (ibid., p. 95). Um outro grupo com inserção "produtiva" baseada em ativo de qualificação é o dos trabalhadores qualificados. Entretanto, embora não sejam detentores de qualificações credenciadas, caracterizam-se por constituírem uma força de trabalho com maior grau de complexidade comparativamente aos segmentos em atividades consideradas menos complexas.

Os trabalhadores manuais caracterizam-se por serem destituídos de meios de produção e de ativos em qualificação, bem como por assumirem posição subordinada na estrutura de poder nos estabelecimentos em que atuam. Constituem uma aproximação do contingente de trabalhadores proletarizados. No presente estudo, foram classificados como trabalhadores manuais na agropecuária, trabalhadores manuais na indústria e trabalhadores manuais ou em funções subalternas nos serviços.

Os trabalhadores não manuais de rotina exercem ocupações de natureza elementar e que não requerem necessariamente formação educacional com nível elevado, tendo, por isso, na sua composição, participações relevantes de trabalhadores envolvidos com atividades administrativas rotineiras. Diversamente, os trabaIhadores não manuais de rotina mais graduados distinguem-se pelo nível educacional mais elevado e pelo exercício de funções de confiança, fazendo jus, normalmente, a gratificações. 
O segmento dos trabalhadores domésticos tem como característica básica o envolvimento com a "produção" de valores de uso para pessoa física ou família frequentemente, embora não exclusivamente, em ambiente domiciliar.

Aborda-se, finalmente, o segmento dos trabalhadores não remunerados. Na realidade, esse segmento de trabalhadores não tem função definida no contexto da divisão do trabalho, apesar da forte recorrência e ampliação na contemporaneidade. É verdade que os trabalhadores não remunerados podem atuar em ajuda a pessoas na condição de empregador, de autoempregado ou trabalhador, porém a atuação mais recorrente tem sido em ajuda a autoempregados, em atividades agropecuárias ou urbanas em situação de precariedade, com vistas à obtenção da renda familiar.

A breve retomada dos procedimentos centrais que nortearam a construção da tipologia de classes foi realizada com o propósito de situar o leitor quanto à sistematização dos dados sobre a estrutura de posições e segmentos de classe. Portanto, pode-se proceder à abordagem empírica do objeto de investigação do estudo.

\section{A estrutura ocupacional segundo a perspectiva de posições e segmentos de classes sociais da Região Metropolitana de Natal na década de 1990}

Pelos dados da Tabela 1, constata-se que de 1991 a 2000 ocorreu uma pequena modificação na estrutura das posições de empregadores, autoempregados e trabalhadores na Região Metropolitana de Natal. A quantidade de empregadores passou de 8.208 para 10.734 pessoas, e a participação relativa de $2,7 \%$ para $2,8 \%$ dos respectivos quantitativos nos anos de 1991 e 2000. Constata-se que, enquanto o número de empregadores cresceu a uma média de $3,1 \%$, o rendimento médio desse contingente cresceu a uma média de $7,8 \%$ ao ano - tendo o rendimento médio passado de 11,0 para 21,5 salários-mínimos mensais. ${ }^{2}$

O quantitativo dos autoempregados passou de 63.661 para 83.028 pessoas, e as participações relativas de $21,0 \%$ para $21,6 \%$. 0 crescimento do número de pessoas foi de $3,0 \%$, porém o rendimento médio cresceu apenas 3,6\% ao ano, por isso o rendimento médio passou de 2,7 para 3,7 salários-mínimos.

No caso dos trabalhadores, o contingente passou de 231.011 para 291.083 pessoas, e a participação relativa de $76,3 \%$ para $75,6 \%$. As taxas de crescimento no período foram de $2,6 \%$, no caso do quantitativo das pessoas, e de apenas $0,5 \%$ ao ano, no caso do rendimento médio, de modo que este passou de 3,1 para 3,2 salários-mínimos mensais, aproximadamente. Em que pese algum dinamismo do mercado de trabalho no período, contata-se a ocorrência de uma relativa estabilidade no que concerne às participações das posições de classe dos empregadores, autoempregadores e dos trabalhadores. Além disso, ocorreram modificações acentuadas nos rendimentos médios dos três agrupamentos de pessoas ocupadas. Enquanto o rendimento médio dos trabalhadores cresceu $19,1 \%$, em todo o período, no caso dos autoempregados o crescimento foi de $37,2 \%$ e, no dos empregadores, foi de $95,8 \%$, demonstrando que o grande dinamismo dos rendimentos ocorrido no 
mercado de trabalho da Região Metropolitana de Natal, comparativamente ao do Rio Grande do Norte e ao Brasil, teve nos empregadores os maiores ganhadores.

Com vistas à obtenção de uma compreensão mais acurada da estrutura de classe durante a década de 1990, procede-se à segmentação das três posições já aludidas. O segmento dos grandes empregadores permaneceu inalterado durante toda a década de 1990, em torno de 2.030 pessoas. Por esse motivo, sua participação relativa oscilou de 0,7\% para 0,5\% de 1991 a 2000 . É necessário destacar a impossibilidade de operacionalizar a quantidade dos grandes empregadores segundo o critério do emprego de 100 ou mais pessoas, conforme se pretendia, em decorrência de limitações nos censos. Logo, os grandes empregadores estão representados no grupo dos que empregaram 10 ou mais pessoas em 1991 e 11 ou mais pessoas no ano de 2000. Certamente, não restam dúvidas quanto à diminuta parcela que o segmento dos grandes empregadores representou da população ocupada na Região Metropolitana de Natal, a exemplo do que ocorreu em meados da década de 1990 na pesquisa realizada por Santos (2002).

Tabela 1 - Tipologia de posições e segmentos de classe - RMNatal (1991 e 2000)

\begin{tabular}{|c|c|c|c|c|c|c|c|c|}
\hline \multirow{3}{*}{ Posições/segmentos de classe } & \multicolumn{4}{|c|}{ Pessoal ocupado } & \multicolumn{2}{|c|}{ Rendimento médio } & \multicolumn{2}{|c|}{ Variação anual (\%) } \\
\hline & \multicolumn{2}{|c|}{1991} & \multicolumn{2}{|c|}{2000} & \multirow{2}{*}{1991} & \multirow{2}{*}{2000} & \multirow{2}{*}{$\begin{array}{l}\text { Pessoal } \\
\text { ocupado }\end{array}$} & \multirow{2}{*}{$\begin{array}{l}\text { Rendimento } \\
\text { médio }\end{array}$} \\
\hline & Quantidade & $\%$ & Quantidade & $\%$ & & & & \\
\hline Empregadores & 8.208 & 2,7 & 10.734 & 2,8 & 10,9 & 21,52 & 3,1 & 7,8 \\
\hline Grandes empregadores & 2.031 & 0,7 & 2.028 & 0,5 & 16,93 & 41,33 & $(0,0)$ & 10,5 \\
\hline Pequenos empregadores mais capitalizados & 3.995 & 1,3 & 4.453 & 1,2 & 9,44 & 22,85 & 1,2 & 10,4 \\
\hline Pequenos empregadores menos capitalizados & 2.183 & 0,7 & 4.254 & 1,1 & 8,28 & 10,68 & 7,8 & 2,9 \\
\hline Auto-empregados & 63.661 & 21,0 & 83.028 & 21,6 & 2,66 & 3,65 & 3,0 & 3,6 \\
\hline Auto-empregados na agropecuária & 7.461 & 2,5 & 5.900 & 1,5 & 1,62 & 1,69 & $(2,6)$ & 0,5 \\
\hline Auto-empregados urbanos descapitalizados & 35.535 & 11,7 & 43.843 & 11,4 & 1,12 & 1,19 & 2,4 & 0,6 \\
\hline Auto-empregados urbanos capitalizados & 19.621 & 6,5 & 29.544 & 7,7 & 5,17 & 6,15 & 4,7 & 2,0 \\
\hline Auto-empregados especialistas & 1.044 & 0,3 & 3.742 & 1,0 & 15,26 & 15,84 & 15,4 & 0,4 \\
\hline Trabalhadores & 231.011 & 76,3 & 291.083 & 75,6 & 3,05 & 3,19 & 2,6 & 0,5 \\
\hline Trabalhadores - dirigentes do setor privado (credenciados) & 1.456 & 0,5 & 2.214 & 0,6 & 15,52 & 13,33 & 4,8 & $(1,7)$ \\
\hline Trabalhadores - dirigentes do setor privado (não credenciados) & 6.006 & 2,0 & 5.950 & 1,5 & 5,67 & 5,81 & $(0,1)$ & 0,3 \\
\hline Trabalhadores - dirigentes do setor público (credenciados) & 1.648 & 0,5 & 1.122 & 0,3 & 13,89 & 17,47 & $(4,2)$ & 2,6 \\
\hline Trabalhadores - dirigentes do setor público (não credenciados) & 1.365 & 0,5 & 840 & 0,2 & 6,74 & 8,35 & $(5,3)$ & 2,4 \\
\hline Trabalhadores especialistas & 9.373 & 3,1 & 12.994 & 3,4 & 13,61 & 14,48 & 3,7 & 0,7 \\
\hline Trabalhadores qualificados & 16.128 & 5,3 & 32.981 & 8,6 & 5,69 & 5,16 & 8,4 & $(1,1)$ \\
\hline Trabalhadores manuais na agropecuária & 13.501 & 4,5 & 7.799 & 2,0 & 0,93 & 1,22 & $(6,0)$ & 3,2 \\
\hline Trabalhadores manuais na indústria & 41.673 & 13,8 & 45.254 & 11,8 & 1,75 & 1,69 & 0,9 & $(0,4)$ \\
\hline Trabalhadores manuais/funções subalternas nos serviços & 70.876 & 23,4 & 92.098 & 23,9 & 2,15 & 2,14 & 3,0 & $(0,1)$ \\
\hline Trabalhadores não manuais de rotina & 35.268 & 11,6 & 38.085 & 9,9 & 2,69 & 2,71 & 0,9 & 0,1 \\
\hline Trabalhadores não manuais mais graduados & 8.353 & 2,8 & 13.682 & 3,6 & 5,61 & 4,49 & 5,7 & $(2,5)$ \\
\hline Trabalhadores domésticos & 23.068 & 7,6 & 30.457 & 7,9 & 0,78 & 1,00 & 3,2 & 2,9 \\
\hline Trabalhadores sem remuneração & 2.298 & 0,8 & 7.607 & 2,0 & - & - & 14,4 & - \\
\hline Total & 302.880 & 100,0 & 384.845 & 100,0 & 3,19 & 3,80 & 2,7 & 2,0 \\
\hline
\end{tabular}

Fonte: Censo Demográfico, IBGE, 1991 e 2000 (Microdados). 
A permanência quantitativa do segmento dos grandes empregadores revela, de certo modo, a existência de "barreiras à entrada" nesse grupo, sendo o óbice fundamental o controle de ativos de capital que se traduz em propriedade rural ou em fábricas, estabelecimentos comerciais e de prestação de serviços diversos.

No que concerne aos rendimentos, constata-se que os grandes empregadores constituíram o segmento de classe que recebeu os maiores valores nos dois anos, bem como obteve os maiores acréscimos dessa variável no período. 0 rendimento médio passou de quase 17, em 1991, para pouco mais de 41 salários-mínimos mensais, em 2000, implicando uma taxa de crescimento de $10,5 \%$ ao ano e de $144 \%$ em todo o período, colocando os grandes empregadores na situação de maiores beneficiários na divisão da renda gerada na Região Metropolitana de Natal na década de 1990. Esse resultado foi, certamente, decorrente de uma expansão econômica relativamente baixa, mas também da existência de grande contingente de desempregados e de um excedente estrutural de força de trabalho em âmbito local, bem como de um ambiente institucional e político pouco propício ao exercício de ações reivindicatórias por parte dos trabalhadores.

É importante ainda destacar, pondo em foco apenas o último ano do período estudado (2000), que, no plano dos subsetores de atividade, as maiores participações relativas dos grandes empregadores ocorreram nos serviços distributivos $(35,7 \%)$ e na indústria de transformação, construção civil e pesada e serviços de utilidade pública $(20,4 \%)$, enquanto as menores frequências ocorreram na agropecuária $(5,9 \%)$ e na indústria extrativa mineral $(1,1 \%)$.
Tais dados denotam que as atividades urbanas se constituíram o lócus privilegiado de acumulação de riqueza, no período em pauta, comparativamente às atividades não urbanas.

Os demais empregadores são os pequenos empregadores mais capitalizados e os pequenos empregadores menos capitalizados. Foram considerados como mais capitalizados os que empregaram de 3 a 9 pessoas, em 1991, e que empregaram de 3 a 10, em 2000; e considerados menos capitalizados, em ambos os anos, os que empregaram 1 ou 2 pessoas. Esclarece-se que os grupos não foram rigorosamente os mesmos nos dois anos, em decorrência da forma como os dados encontram-se organizados nas fontes da pesquisa. A ideia de segmentação dos pequenos empregadores teve como propósito separar os empregadores que não têm condições de viver exclusivamente do trabalho de outrem dos que têm menos necessidade de trabalhar, uma vez que os aportes de capitais permitem comando sobre uma quantidade maior de trabalhadores.

Os pequenos empregadores mais capitalizados experimentaram uma taxa de crescimento relativamente baixa no seu contingente e, por isso, perderam importância relativa, passando de 1,3\%, em 1991, para 1,2\% das pessoas ocupadas em 2000. Por sua vez, os pequenos empregadores menos capitalizados experimentaram considerável incremento e tiveram a participação ampliada de $0,7 \%$ para $1,1 \%$. No que concerne ao rendimento médio, observa-se que, enquanto, no período, o crescimento no caso dos pequenos empregadores menos capitalizados foi de $29 \%$, no caso dos mais capitalizados foi de aproximadamente $142 \%$.

No que se refere às ocupações, constata-se que os pequenos empregadores mais capitalizados se distribuíram por 49 e os pequenos 
empregadores menos capitalizados por 37 grupos ocupacionais, porém $68,4 \%$ dos casos do primeiro segmento ocorreram em apenas dois grupos - dirigentes de empresas (empregadores com mais de 5 empregados) e gerentes de produção e operações - e 67,4\% dos casos do segundo segmento em apenas um grupogerentes de produção e operações.

Embora os dados dos censos não possibilitem demonstração, é razoável supor que parte do crescimento do número de pequenos empregadores tenha ocorrido em decorrência da privatização de empresas públicas e da entrada em vigor de planos de demissão voluntária no setor público, possibilitando aportes mínimos de capitais para o início de atividades econômicas, em um ambiente ideológico de ascensão do "empreendedorismo".

A análise da posição dos autoempregados é iniciada pelo segmento dos autoempregados especialistas ou detentores de ativos de qualificação credenciada. Trata-se do segmento que aglutina os "profissionais liberais típicos", mas incorpora também os detentores de conhecimentos técnicos que constituem perícia em novas atividades econômicas.

O segmento dos autoempregados especialistas foi, dentre todos os segmentos de classe, aquele em que ocorreu o maior crescimento de integrantes no período $1991 / 2000$, sendo de $258,2 \%$ ou o equivalente a $15,4 \%$ ao ano, de modo que a participação no total das pessoas ocupadas passou de $0,3 \%$ para $1,0 \%$. Embora se trate de uma participação baixa, é necessário considerar que a expansão no período foi expressiva. No tocante ao nível do rendimento médio, é importante ressaltar que, ainda que o crescimento, ao longo do período estudado, tenha sido muito baixo, o seu nível, no ano de 1991, foi superior ao dos dois segmentos de pequenos empregadores e, no ano de 2000 , foi ainda superior ao do segmento dos pequenos empregadores menos capitalizados.

No ano de 2000, a participação dos grupos ocupacionais na composição do segmento dos autoempregados especialistas revela que este foi integrado majoritariamente por tradicionais integrantes de profissões liberais: advogados $(23,1 \%)$, cirurgiões-dentistas $(17,9 \%)$, contadores e auditores $(15,1 \%)$ e médicos (11,2\%). Vale ainda destacar que grupos ocupacionais vinculados às atividades econômicas mais recentes, tais como técnicos em programação, analistas de sistemas, programadores de informática e técnicos em operação de computadores, representaram conjuntamente $6,1 \%$ do total dos integrantes do segmento dos autoempregados, e mais de 70\% dessa participação concentrou-se no primeiro grupo.

Os não detentores de ativos de qualificação credenciada foram classificados, inicialmente, em autoempregados não especialistas em atividades rurais ou urbanas. Os autoempregados na agropecuária tiveram o seu quantitativo diminuído à taxa de $2,6 \%$ ao ano, uma das piores dentre os vinte segmentos, implicando uma perda de posição relativa de $2,5 \%$ para $1,5 \%$ no total da ocupação. No que concerne ao rendimento médio, constatou-se um acréscimo de 0,5\% ao ano, de modo que foi atingido o nível de 1,7 salário-mínimo no ano de 2000 , dando clara indicação da situação de precariedade das atividades exercidas pelos autoempregados na agropecuária. É importante destacar que, em 2000,71,0\% do total das ocupações desse segmento de classe correspondeu ao grupo ocupacional produtores agrícolas e $19,7 \%$ ao grupo pescadores e caçadores, e os grupos de atividade que mais 
ocuparam pessoas na condição de autoempregados na agropecuária foram os seguintes: cultivos agrícolas mal especificados (33,6\%), pesca e serviços relacionados (18,3\%).

Os autoempregados urbanos foram definidos em função dos diferentes aportes de capital, por isso foram classificados em autoempregados descapitalizados e autoempregados capitalizados. Foram considerados descapitalizados os autoempregados com rendimento médio inferior a dois salários-mínimos mensais. Esse procedimento foi adotado levando-se em consideração o fato de que, se um autoempregado aufere tal rendimento e tem esposa e dois filhos, o valor da renda média familiar per capita será inferior a $1 / 2$ salário-mínimo, que é considerado o valor monetário que constituiu a "linha da pobreza" no período em estudo. Os que auferiram rendimentos superiores a dois salários-mínimos foram considerados capitalizados.

Os autoempregados descapitalizados e os autoempregados capitalizados tiveram os seus contingentes acrescidos às taxas de $2,4 \%$ e $4,7 \%$, respectivamente, no período $1991 / 2000$, por isso o primeiro segmento teve sua participação reduzida de $11,7 \%$ para $11,4 \%$ e o segundo a sua elevada de $6,5 \%$ para $7,7 \%$ nos citados anos. No que concerne aos rendimentos dos autoempregados, constata-se que os incrementos ocorridos no período e os seus níveis médios reforçam também a constatação da situação de precariedade dos descapitalizados e que os maiores aportes de capital se constituíram condição fundamental para a melhor situação apresentada pelos capitalizados.

No que diz respeito às ocupações, constata-se que os descapitalizados se distribuíram por 133 e os capitalizados por 129 grupos ocupacionais, porém $51,1 \%$ dos casos do primeiro segmento concentraram em apenas cinco grupos ocupacionais e $57,0 \%$ dos casos do segundo segmento ocorreram em apenas sete grupos. Vale destacar que quatro grupos ocupacionais foram comuns aos dois segmentos - trabalhadores nos serviços de higiene e embelezamento, vendedores e demonstradores em lojas ou mercados, vendedores ambulantes e trabalhadores de estruturas de alvenaria.

Em seguida, procede-se à análise do agrupamento dos trabalhadores. Estes caracterizam-se, via de regra, por assumir posição de subordinação hierárquica em relação ao empregador. Entretanto, a estrutura das ocupações exercidas pelos trabalhadores, expressão da divisão do trabalho em dado momento histórico, implica a constituição de vários segmentos profissionais. Alguns segmentos, conforme já mencionado, exercem posições de autoridade nas instituições em que atuam, ancoradas em ativos organizacionais - poder conferido pelo exercício de cargos ou funções fundados no mando. Essas posições são exercidas pelos segmentos dos trabaIhadores que atuam como dirigentes no setor privado ou no setor público. Como os níveis de poder exercidos por esses segmentos não são homogêneos, procedeu-se à segmentação dos trabalhadores-dirigentes segundo níveis de escolaridade, para separar os que exerciam cargos e funções de direção e possuíam qualificação credenciada. Foram considerados credenciados os detentores de cursos superiores (15 ou mais anos de estudo).

Enfocam-se, inicialmente, os trabalhadores-dirigentes do setor privado. Com base na Tabela 1, a ocorrência de crescimento do número de dirigentes do setor privado 
credenciados e pequeno decréscimo do número de dirigentes do setor privado não credenciados. As distintas dinâmicas fizeram com que o primeiro segmento tivesse sua participação elevada de $0,5 \%$ para $0,6 \%$ e o segundo a sua reduzida de $2,0 \%$ para $1,5 \%$ do total das pessoas ocupadas. No que diz respeito aos rendimentos, observa-se a ocorrência de declínio no rendimento médio dos dirigentes credenciados à taxa de $1,7 \%$ e elevação do rendimento médio dos não credenciados à taxa de $0,3 \%$ ao ano. Apesar de tais performances, os níveis dos rendimentos em vigor no ano de 2000 são reveladores de que as posições de mando ancoradas em qualificações credenciadas foram mais bem remuneradas do que as não credenciadas. No citado ano, enquanto o rendimento médio dos dirigentes credenciados foi de aproximadamente 13,3 , o dos não credenciados foi em torno de 5,8 salários-mínimos.

Os segmentos dos dirigentes do setor público credenciados e dos dirigentes do setor público não credenciados experimentaram decréscimos dos seus contingentes no período 1991/2000. No caso do primeiro, o decréscimo foi de uma taxa de $4,2 \%$ e, no do segundo, de $5,3 \%$ ao ano. Por esse motivo, experimentaram perda de participação relativa no conjunto dos integrantes do mercado de trabalho. Não obstante o decréscimo dos seus contingentes, ambos os segmentos de classe experimentaram acréscimos nos rendimentos, sendo, no caso dos dirigentes credenciados, superiores aos dos não credenciados. Dado que os reajustes não integraram a agenda dos servidores públicos, durante a década de 1990 , sobretudo a partir da implantação do Plano Real, torna-se evidente que apenas alguns segmentos devidamente selecionados experimentaram reajustes, embora a taxas baixas.
Sem dúvida, o poder entre os dirigentes do setor público encontra-se concentrado nos representantes dos poderes executivo, legislativo, judiciário, nos oficiais da forças armadas e nos dirigentes das principais instituições públicas, porém, ao final do período estudado, os principais grupos concentradores de dirigentes do setor público, dada a impossibilidade de apresentar separadamente as citadas ocupações, foram: dirigentes das áreas de apoio da administração pública, dirigentes de produção e operações da administração pública, dirigentes e administradores de organização de interesse público e militares das três forças. Em primeiro lugar, vale destacar que Natal é uma das poucas capitais estaduais que sediam as três forças armadas. Em segundo, a forte presença militar, em Natal e Parnamirim, constitui a permanência de uma marca do passado na contemporaneidade, sendo a primeira intitulada "cidade militar" em decorrência das intervenções espaciais norte-americanas e das forças armadas brasileiras dos anos 1940 aos anos 1950 (Lopes Jr., 2000).

Os trabalhadores especialistas ou com domínio de sistemas peritos representaram $3,1 \%$ e $3,4 \%$ dos respectivos totais das pessoas ocupadas em 1991 e 2000, em decorrência de crescimento médio anual de $3,7 \%$ do quantitativo das pessoas do segmento. Vale ainda pôr em relevo que o rendimento médio do segmento em foco foi de 13,6 e 14,5 salários-mínimos nos anos em pauta, indicando a importância social conferida às qualificações credenciadas que permitem a atuação na condição de trabalhadores especialistas. No ano de 2000, constituíram-se os principais grupos ocupacionais do segmento trabalhadores especialistas: professores de ensino superior, programadores, avaliadores e orientadores de 
ensino, serventuários da justiça e afins, médicos, contadores e auditores e técnicos em operação de computadores.

Os trabalhadores qualificados, ou força de trabalho relativamente complexa, constituíram o segmento com o sétimo maior contingente de pessoas, em 1991, e o quinto em 2000 , tendo apresentado uma das maiores taxas de crescimento, 8,4\% ao ano, no período. Constata-se que o rendimento médio seguiu uma trajetória diversa da apresentada pelo quantitativo dos integrantes. Os principais grupos ocupacionais dos trabalhadores qualificados foram: técnicos e auxiliares de enfermagem, professores de disciplinas da educação geral do ensino médio, mecânicos de manutenção de veículos automotores, militares do exército e supervisores de serviços administrativos (exceto contabilidade), dentre outros.

Os trabalhadores manuais na agropecuária constituíram o segmento de classe que experimentou a maior queda da quantidade de pessoas ao longo da década de 1990. Por esse motivo, foi o segmento com a maior mudança de posição relativa entre 1991 e 2000. Em que pese tal comportamento na quantidade de trabalhadores, o segmento em foco experimentou um incremento médio anual de $3,2 \%$ no rendimento médio. Apesar da performance, em 2000, o rendimento do segmento foi de apenas 1,22 salário-mínimo mensal - um dos piores rendimentos dentre todos os segmentos de classe, denotando precariedade do indicador e das condições de vida dos integrantes do segmento.

0 efetivo de trabalhadores manuais na indústria cresceu à média anual de 0,9\%. Apesar da performance, o segmento apresentou, em ambos os anos, o segundo maior número de pessoas, revelando que se trata de importante segmento de classe na Região Metropolitana de Natal. Observa-se que, nesse segmento de classe, ocorreu decréscimo do rendimento médio ao longo do período estudado de 1,8 para 1,7 salário-mínimo. Na realidade, essa informação apenas corrobora a discussão já empreendida sobre a reestruturação no setor industrial da Região Metropolitana que implicou forte rigor sobre a força de trabalho, sobretudo a proletarizada, que costuma enfrentar forte concorrência de amplos contingentes de trabalhadores aptos a atuarem no setor, bem como de pessoas que atuam na condição de terceirizados. Os principais grupos do segmento foram operadores de máquinas de costura de roupas $(15,8 \%)$, trabalhadores de estruturas de alvenaria $(14,2 \%)$ e ajudantes de obras civis $(13,2 \%)$.

O segmento dos trabalhadores manuais ou em funções subalternas nos serviços teve o seu contingente humano alterado de 70.876 para 92.098 pessoas, implicando aumento de participação na composição da ocupação de $23,4 \%$ para $23,9 \%$ e fazendo com que o segmento continuasse como aglutinador do maior número de pessoas dentre todos os segmentos. Pode-se constatar que, nesse segmento de classe, o rendimento médio permaneceu estagnado por uma década, por volta dos 2,1 salários-mínimos. Deve ser registrado que se constituiu no segmento proletarizado com o maior rendimento médio na Região Metropolitana de Natal na década de 1990.

O efetivo dos trabalhadores não manuais de rotina é composto, em boa medida, por pessoas que atuam em ocupações administrativas rotineiras, em ocupações que não requerem nível de formação muito elevado, e por professores situados na base do sistema educacional. Na Região Metropolitana 
de Natal, o contingente dos trabalhadores pertencentes a esse segmento de classe foi o quarto maior em ambos os anos em estudo. O segmento concentrou-se principalmente nos seguintes grupos ocupacionais: professores de nível médio no ensino fundamental $(22,7 \%)$, secretários de expediente e estenógrafos $(15,1 \%)$ e recepcionistas $(12,4 \%)$. 0 rendimento médio dos trabalhadores não manuais de rotina foi superior ao dos três segmentos de trabalhadores manuais e inferior ao dos trabalhadores qualificados bem como dos trabalhadores de rotina mais graduados, tornando claro que ativos de qualificação e posições hierárquicas diferenciadas na estrutura das ocupações se refletem nos rendimentos auferidos.

O conjunto dos trabalhadores não manuais de rotina mais graduados apresentou elevada taxa de crescimento do número de pessoas e teve a participação elevada de 2,8\% para $3,6 \%$. No ano de 2000 , concentrou-se nos seguintes grupos ocupacionais: escriturários em geral, agentes, assistentes e auxiliares administrativos $(60,9 \%)$ e representantes comerciais e técnicos de vendas $(24,1 \%)$.

O segmento dos trabalhadores domésticos, caracterizado pela "produção" de valores de uso para unidades familiares, teve importante peso para a ocupação na Região Metropolitana de Natal durante a década de 1990. O seu contingente passou de 23.068 para 30.457 pessoas de 1991 a 2000. Trata-se do segmento de trabalhadores remunerados com os menores níveis de rendimento médio, pois, em 1991, fora de 0,78 e atingiu, em 2000, 1,00 salário-mínimo, significando que o incremento médio anual de 2,9\% apenas cumpriu a importante função de situar os trabalhadores do segmento em pauta no salário-mínimo legal. Não obstante se tratar de um valor muito baixo, é importante destacar que mudanças institucionais e pressões sociais foram decisivas para que o rendimento médio do segmento dos trabalhadores domésticos atingisse o nível de 1,0 salário-mínimo no ano em pauta e para que a Constituição Federal de 1988, artigo 70 dos Direitos sociais, inciso IV, fosse cumprida para o "empregado doméstico" (Brasil, 2006). Para reforçar tal posição, é importante destacar que, no ano de 1980, no Censo Demográfico do mesmo ano, o rendimento médio do grupo ocupacional "empregadas domésticas" foi de apenas 0,4 salário-mínimo (Clementino, 1995, p. 313). Deve ainda ser acrescentado que apenas o grupo ocupacional trabalhadores dos serviços domésticos em geral foi responsável pela ocupação de $95,2 \%$ do total de pessoas do segmento dos trabalhadores domésticos, mas, mesmo que com participações bem menores, também apareceram os seguintes grupos ocupacionais: atendentes de creche e acompanhantes de idosos (2,2\%), cozinheiros $(1,3 \%)$, guardas e vigias $(0,3 \%)$, dentre outros. Constata-se que a mudança no padrão habitacional ocorrida na Região Metropolitana de Natal desde meados dos anos 1980, caracterizado por edificações verticalizadas, induziu a mudanças na natureza do trabalho doméstico, ao incorporar, a esse trabaIho, funções somente possíveis no contexto de uma demanda exercida por segmentos sociais detentores de poder aquisitivo relativamente elevado e, portanto, com capacidade para usufruir, em ambiente doméstico, de serviços especiais que promoveram alterações qualitativas no trabalho doméstico no sentido existente tradicionalmente. 
Aborda-se, finalmente, o segmento dos trabalhadores não remunerados. 0 quantitativo de pessoas integrantes desse segmento cresceu $231 \%$ no período, passando de 2.298 para 7.607 pessoas. No mesmo ano de 2000 , embora tal efetivo tenha sido distribuído por cento e doze grupos ocupacionais, apenas quatro, reconhecidamente precários, agregaram aproximadamente metade das ocupações: trabalhadores agrícolas (19,6\%), vendedores e demonstradores em lojas ou mercados $(19,1 \%)$, vendedores ambulantes $(5,7 \%)$ e garçons, barmen e copeiros $(5,4 \%)$.

Por fim, pode-se concluir que, entre os empregadores, o controle de aportes de capitais relativamente elevados foi fundamental para a participação no processo de apropriação da renda gerada na Região Metropolitana de Natal na década de 1990. Entre os autoempregados, o fator que se revelou mais importante para a participação no mercado de trabalho e na repartição da renda foi a posse de ativos de qualificação. Os demais autoempregados, mesmo os considerados capitalizados, não lograram bom usufruto na distribuição da renda no período em destaque. No conjunto dos trabalhadores, de um modo geral, os segmentos que obtiveram os melhores resultados, ao menos no que diz respeito aos níveis dos rendimentos, foram aqueles cuja participação no processo de produção ou de prestação de serviços se ancorou em qualificações credenciadas ou relacionadas a posições que envolveram mando ou liderança. Já os segmentos envolvidos em situações de trabaIho com caráter precário, embora em alguns casos tenham experimentado considerável incremento nos rendimentos, no que concerne aos níveis desses rendimentos, mantiveram-se situados na base da distribuição. Essa situação, decerto, teve como condicionante fundamental a existência de um ambiente social e político desfavorável às lutas reivindicatórias dos trabalhadores ao longo da última década do século XX, na Região Metropolitana de Natal.

\section{Considerações finais}

A título de considerações finais, constata-se um relativo "congelamento" das classes sociais na Região Metropolitana de Natal, ao longo da década de 1990, ao se considerar as posições de classe empregadores, autoempregados e trabalhadores. No entanto, observando a estratificação das aludidas posições, constatam-se casos fortuitos de mudanças nas posições relativas do quantitativos de pessoas ou mesmo dos rendimentos médios. Entretanto é importante resgatar a ideia-força representada pela hipótese: em contexto de baixo dinamismo da economia e do mercado de trabalho, a distribuição de ativos físicos, financeiros, de qualificação e de assunção de posições de mando foi decisiva para um certo "congelamento" da situação de classe na Região Metropolitana de Natal, sendo os maiores ganhadores os grandes empregadores, não obstante a fragilidade da fonte em destacá-los, e em menor grau os detentores de ativos de qualificação ou organizacionais. Os trabalhadores destituídos desses ativos permaneceram plantados na base da estrutura de classes. 


\section{[I] https://orcid.org/0000-0002-2382-5094}

Universidade Federal do Rio Grande do Norte, Centro de Ciências Sociais Aplicadas, Departamento de Economia. Natal, RN/Brasil.

marconi.br62@gmail.com

\section{Nota de agradecimento}

Agradeço aos professores Maria do Livramento M. Clementino e Denílson da Silva Araújo pelas contribuições dadas ao presente artigo. Entretanto, ressalto que a persistência de eventuais erros são de minha estrita responsabilidade.

\section{Notas}

(1) A difusão dos microdados dos censos demográficos tem motivado a realização de estudos, abordando a estrutura ocupacional nas áreas metropolitanas do Brasil, tendo o "Observatório das Metrópoles" assumido importante posição nessa discussão. Por esse motivo, vale destacar que o "Observatório" desenvolveu uma tipologia sócio-ocupacional para o estudo dos grandes espaços urbanos brasileiros a partir dos microdados dos censos demográficos. Essa tipologia sócio-ocupacional é composta por oito agrupamentos que resultam da agregação de vinte e quatro categorias ocupacionais que, por sua vez, são resultantes do agrupamento dos grupos ocupacionais constantes dos censos demográficos.

(2) Para uma visão sintética da metodologia de Tipologias de posições e segmentos de classe utilizada no estudo consultar o Quadro anexo.

Para ter acesso ao detalhamento sobre as Tipologias de posições e segmentos de classe de 1991 e 2000, consultar o repositório de teses da Universidade Federal do Rio Grande do Norte ou enviar solicitação para o e-mail: marconi.br62@gmail.com.

\section{Referências}

BRASIL (2006). Constituição da República Federativa do Brasil. Brasília.

BRAVERMAN, H. (1977). Trabalho e capital monopolista. Rio de Janeiro, Zahar.

CLEMENTINO, M. do L. M. (1995). Economia e urbanização: o Rio Grande do Norte nos anos 70. Natal, UFRN/CCHLA.

GIDDENS, A. (1975). A estrutura de classes das sociedades avançadas. Rio de Janeiro, Zahar. 
IBGE (1991). Censo Demográfico. (Microdados).

(2000). Censo Demográfico. (Microdados).

LOPES JÚNIOR, E. (2000). A construção social da cidade do prazer. Natal, EDUFRN.

MAIA, A. G. (2006). Espacialização de classes no Brasil: uma nova dimensão para a análise social. Tese de doutorado. Campinas, Universidade Estadual de Campinas.

MILLS, W. (1979). A nova classe média. Rio de Janeiro, Zahar.

POULANTZAS, N. (1978). As classes sociais no capitalismo de hoje. Rio de Janeiro, Zahar.

QUADROS, W. (2003). Aspectos da crise social no Brasil dos anos oitenta e noventa. Tese de livre docência. Campinas, Universidade Estadual de Campinas.

SANTOS, J. A. F. (2002). Estrutura de posições de classe no Brasil: mapeamento, mudanças e efeitos na renda. Belo Horizonte, Editora da UFMG/Rio de Janeiro, Iuperj.

SILVA, M. G. da S. (2008). Mercado de trabalho, ocupações e rendimentos: a Região metropolitana de Natal na década de 1990. Tese de doutorado. Natal, Universidade Federal do Rio Grande do Norte.

WRIGHT, E. O. et al. (1989). The debate on classes. Londres, Verso. (1997). Class counts: comparative studies in classes analysis. Cambridge, Cambridge University Press.

WRIGHT, E. O. (1981). Classe, crise e o Estado. Rio de Janeiro, Zahar.

Texto recebido em 26/ago/2020

Texto aprovado em 7/dez/2020 
ANEXO

Tipologia de posições e segmentos de classes sociais

\begin{tabular}{|c|c|}
\hline $\begin{array}{l}\text { Posições e segmentos } \\
\text { de classes sociais }\end{array}$ & Critérios metodológicos \\
\hline 1) Grandes empregadores & $\begin{array}{l}\text { Empregadores que empregaram } 10 \text { ou mais pessoas no estabelecimento (1991). } \\
\text { Empregadores que empregaram } 11 \text { ou mais pessoas no estabelecimento (2000). }\end{array}$ \\
\hline $\begin{array}{l}\text { 2) Pequenos empregadores } \\
\text { mais capitalizados }\end{array}$ & $\begin{array}{l}\text { Empregadores que empregaram de } 3 \text { a } 9 \text { pessoas no estabelecimento (1991). } \\
\text { Empregadores que empregaram de } 3 \text { a } 10 \text { pessoas no estabelecimento (2000). }\end{array}$ \\
\hline $\begin{array}{l}\text { 3) Pequenos empregadores } \\
\text { menos capitalizados }\end{array}$ & $\begin{array}{l}\text { Empregadores que empregaram de } 1 \text { a } 2 \text { pessoas no estabelecimento. Os pequenos } \\
\text { empregadores pouco capitalizados especialistas (cujos grupos ocupacionais integraram o } \\
\text { segmento especialistas) foram reclassificados como autoempregados especialistas. }\end{array}$ \\
\hline 4) Autoempregados na agropecuária & Posições na ocupação de "conta própria" em atividades agropecuárias. \\
\hline $\begin{array}{l}\text { 5) Autoempregados urbanos } \\
\text { descapitalizados }\end{array}$ & $\begin{array}{l}\text { Posição na ocupação de "conta própria" em atividades não agropecuárias. Critério para } \\
\text { composição do segmento: rendimento mensal inferior a } 2 \text { salários-mínimos. }\end{array}$ \\
\hline $\begin{array}{l}\text { 6) Autoempregados urbanos } \\
\text { capitalizados }\end{array}$ & $\begin{array}{l}\text { Posição na ocupação de "conta própria" em atividades não agropecuárias. Critério para } \\
\text { composição do segmento: rendimento mensal igual ou superior a } 2 \text { salários-mínimos. }\end{array}$ \\
\hline 7) Autoempregados especialistas & $\begin{array}{l}\text { Posição na ocupação de "conta-própria" e especialista por título ou grupo ocupacional, } \\
\text { conforme categorização de especialista usada na tipologia. Autoempregados especialistas } \\
\text { com menos de } 15 \text { anos de estudo foram reclassificados, distribuídos como autoempregados } \\
\text { urbanos de acordo com o nível do rendimento. }\end{array}$ \\
\hline $\begin{array}{l}\text { 8) Trabalhadores - dirigentes } \\
\text { do setor privado (credenciados) }\end{array}$ & $\begin{array}{l}\text { Empregados conforme a categoria de posição na ocupação; gerentes ou supervisores por } \\
\text { título ou grupo ocupacional e "empregados" no exercício de funções de direção no setor } \\
\text { privado. O critério para a classificação como credenciado foi a posse de } 15 \text { ou mais anos de } \\
\text { estudo. }\end{array}$ \\
\hline $\begin{array}{l}\text { 9) Trabalhadores - dirigentes } \\
\text { do setor privado (não credenciados) }\end{array}$ & $\begin{array}{l}\text { Empregados conforme a categoria de posição na ocupação; gerentes ou supervisores por } \\
\text { título ou grupo ocupacional e "empregados" no exercício de funções de direção no setor } \\
\text { privado. O critério para a classificação como credenciado foi a posse de menos de } 15 \text { anos } \\
\text { de estudo. }\end{array}$ \\
\hline $\begin{array}{l}\text { 10) Trabalhadores - dirigentes } \\
\text { do setor público (credenciados) }\end{array}$ & $\begin{array}{l}\text { Empregados conforme a categoria de posição na ocupação; gerentes ou supervisores por } \\
\text { título ou grupo ocupacional e "empregados" no exercício de funções de direção no setor } \\
\text { público. O critério para a classificação como credenciado foi a posse de } 15 \text { ou mais anos de } \\
\text { estudo. Foram considerados, nesse segmento, apenas os militares das forças armadas com } \\
15 \text { ou mais anos de estudo. Os militares com menos de } 15 \text { anos de estudo foram reclas- } \\
\text { sificados como trabalhadores qualificados. }\end{array}$ \\
\hline $\begin{array}{l}\text { 11) Trabalhadores - dirigentes } \\
\text { do setor público (não credenciados }\end{array}$ & $\begin{array}{l}\text { Empregados conforme a categoria de posição na ocupação; gerentes ou supervisores por } \\
\text { título ou grupo ocupacional e "empregados" no exercício de funções de direção no setor } \\
\text { público. O critério para a classificação como credenciado foi a posse de menos de } 15 \text { anos } \\
\text { de estudo. }\end{array}$ \\
\hline 12) Trabalhadores especialistas & $\begin{array}{l}\text { Empregados conforme a posição na ocupação; especialistas por título ou grupo ocupacio- } \\
\text { nal, notadamente os titulares de profissões credenciadas e detentores de conhecimentos } \\
\text { ou qualificações escassas acerca dos sistemas de excelência técnica ou competência } \\
\text { profissional. Posse de } 11 \text { anos de estudo ou mais (critério de "filtro" para excluir casos dis- } \\
\text { sonantes classificados nos grupos ocupacionais). }\end{array}$ \\
\hline 13) Trabalhadores qualificados & $\begin{array}{l}\text { Empregados conforme a posição na ocupação; trabalhadores qualificados de acordo com o } \\
\text { título ou grupo ocupacional, notadamente trabalhadores de ofício, professores de } 5^{a} \text { a a } 8^{a} \\
\text { séries, professores de } 2 \text { o grau, técnicos e detentores de nível médio, intermediário ou semi- } \\
\text { profissional de conhecimentos ou habilidades escassas. Posse de } 5 \text { anos de estudo ou mais } \\
\text { (critério de "filtro" para excluir casos dissonantes classificados nos grupos ocupacionais). } \\
\text { Inclusão de casos de classificação de especialistas por título ou grupo ocupacional que } \\
\text { foram "filtrados" devido ao fato de terem } 10 \text { ou menos anos de estudo. }\end{array}$ \\
\hline $\begin{array}{l}\text { 14) Trabalhadores manuais } \\
\text { na agropecuária }\end{array}$ & $\begin{array}{l}\text { Empregados conforme a posição na ocupação e trabalhadores manuais na agropecuária } \\
\text { conforme o título ou grupo ocupacional. }\end{array}$ \\
\hline $\begin{array}{l}\text { 15) Trabalhadores manuais } \\
\text { na indústria }\end{array}$ & $\begin{array}{l}\text { Empregado conforme a posição na ocupação e trabalhador manual não agropecuária } \\
\text { segundo o título ou grupo ocupacional. }\end{array}$ \\
\hline $\begin{array}{l}\text { 16) Trabalhadores manuais ou } \\
\text { em funções subalternas nos serviços }\end{array}$ & $\begin{array}{l}\text { Empregado conforme a posição na ocupação e trabalhador manual não agropecuária } \\
\text { segundo o título ou grupo ocupacional. }\end{array}$ \\
\hline
\end{tabular}


17) Trabalhadores não manuais de rotina

18) Trabalhadores não manuais mais graduados

19) Trabalhadores domésticos

20) Trabalhadores sem remuneração
Empregado conforme a posição na ocupação e trabalhador não manual de rotina segundo o título ou grupo ocupacional.

Inclusão de casos dissonantes de classificação de trabalhadores qualificados por título ou grupo ocupacional que foram "filtrados" devido ao fato de possuírem 4 ou menos anos de estudo e cujo perfil de trabalho se aproxima da categoria ocupacional.

Empregado conforme a posição na ocupação e trabalhador não manual mais graduado segundo o título ou grupo ocupacional (em termos de formação profissional/qualificação, exercício de funções delegadas pelo empregador, percepção de gratificações de desempenho ou função típica da ocupação e condicionamentos institucionais vinculados ao setor público de emprego).

Empregados domésticos por posição na ocupação e título ou grupo ocupacional.

Pessoas que se encontravam trabalhando em ajuda a membros da família.

Fonte: tipologia baseada em Santos (2002). 
